\title{
A Study of Risk Factors Associated With the Prevalence of Cryptosporidium in Villages Around Lake Atitlan, Guatemala
}

H. E. Laubach 1 , C. Z. Bentley ${ }^{2}$, E. L.
Ginter $^{2}$, J. S. Spalter
and L. A. Jensen
${ }^{1}$ Department of Microbiology, College of Medical Sciences;
${ }^{2}$ Department of Family Medicine and ${ }^{3}$ Infectious Diseases,
College of Osteopathic Medicine, Health Professions Division,
Nova Southeastern University, Fort Lauderdale, Florida USA

Cryptosporidium parvum is an endemic, zoonotic coccidian parasitosis that is highly prevalent in third-world countries where waterborne fecal contamination of food and drink or person-toperson contact with oocysts are the most common methods of transmission of the enteric protozoan. This type of transmission of the parasite made the villages around Lake Atitlan, Guatemala a unique site to compare environmental risk factors with the level of Cryptosporidium infections in the local residents. The study was carried out in two villages, San Antonio Palopo and Santa Catarina Palopo, located in the highlands above the shores of the lake. Smears from stool specimens of patients with gastroenteritis were processed using Kinyoun's modified acid-fast stain and observed with light microscopy. Of the 100 residents examined from the two villages, $32 \%$ had Cryptosporidium infections. Female children had the highest prevalence of infection (44\% in San Antonio Palopo and $46 \%$ in Santa Catarina Palopo, $p<0.05$ ), and they also had significantly higher infection rates than males, $50 \%$ vs. $17 \%$, respectively. The prevalence rate was not influenced by the season of the year or by the location of the residents. We found differences in prevalence rates due to age and gender, and we suggest that the high infection rates of specific groups are associated with their exposure to the contaminated water supply from Lake Atitlan. Key Words: Cryptosporidium, disease transmission, Guatemala, risk factors, lake-water.

Intestinal cryptosporidiosis is a cause of diarrheal disease, worldwide, with 10 species of Cryptosporidium infecting more than 150 species of mammals [1,2]. The 1993 outbreak of cryptosporidiosis in Milwaukee, Wisconsin, attributed to contaminated city water, produced an estimated 403,000 infections [3]. This endemic, zoonotic coccidian parasitosis is highly prevalent in third-world countries that have waterborne fecal contamination of food and drink

Received on 21 January 2004; revised 13 June 2004.

Address for correspondence: Dr. Harold E. Laubach. Department of Microbiology, College of Medical Sciences, Nova Southeastern University, Ft. Lauderdale, FL 33328, USA. Phone: 954-262-1303. Fax: 954-262-1802.

E-mail: harold@nova.edu

The Brazilian Journal of Infectious Diseases 2004;8(4):319-323 (C) 2004 by The Brazilian Journal of Infectious Diseases and Contexto Publishing. All rights reserved. with oocysts and where there is direct infection by person-to-person contact as the common method of transmission of this enteric protozoan [4].

Diarrhea, following infection with Cryptosporidium, is most common in infants and children in developing countries, in immunosuppressed hosts and in people with deficient nutrition [5-7]. Cryptosporidiosis is a serious disease in these countries, because it increases health problems associated with poverty and malnutrition. Epidemiological changes due to biological differences and sanitation practices of individuals in this population would have an overall effect on disease prevalence. In an attempt to address this point, we examined the risk factors involved in the prevalence of cryptosporidiosis in villages around Lake Atitlan, Guatemala. 


\section{Materials and Methods}

\section{Study population}

The study was carried out in San Antonio Palopo and Santa Catarina Palopo in the highlands of central Guatemala. The two villages are located 12 miles from each other on the shores of Lake Atitlan, a large, freshwater reservoir with streams running into it but without water leaving it, making it a confined water source for the local inhabitants. Data were obtained during two January and June visits in 2001 and in 2002.

Children between the ages of 2 and 13, with symptoms of abdominal pain and acute, watery, diarrhea, were selected for the study. The history of infection with Cryptosporidium, the immune status, prior or current pathogen infections, and the degree of malnutrition of the patients in our study were not known. Therefore, other unidentified pathogens and conditions could have had an affect on our results of risk factors associated with children having abdominal pain and diarrhea and harboring Cryptosporidium.

Of the 100 children in the study, 58 were male and 42 were female. San Antonio Palopo had 21 males and 25 females and Santa Catarina Palopo had 37 males and 17 female participants in the study. The Institutional Review Board of Nova Southeastern University approved the study and informed consent was obtained from subjects, parents or guardians.

\section{Sample collection and laboratory analysis}

Children with symptoms of diarrhea and abdominal pain were identified in the towns of San Antonio Palopo and Santa Catarina Palopo. Fecal samples were collected from patients, and smears were prepared on glass slides by mixing with PVA, followed by drying at room temperature. Dried specimens were transported to a laboratory at NSU and Cryptosporidium oocysts were identified after staining with Kinyoun's modified acid-fast stain [8]. A sample was considered negative for Cryptosporidium if oocysts were not detected after 20 minutes of scanning using oil immersion (1000x) light microscopy.

\section{Statistical analysis}

Infected and non-infected patients were identified, and the number of people infected within age groups, gender and villages was used to determine the prevalence of Cryptosporidium. Comparisons of the prevalence rates of infection between age groups, gender and villages were made using McNemar's test [9]. Differences between groups were considered significant if $p<0.05$.

\section{Results}

All three groups of children in the study had high infection rates (16-44\%) for cryptosporidiosis, and there were no significant differences in the prevalence rates between younger and older age groups (Table 1). In Santa Catarina Palopo, female children in the 2 to 5 year age group had a higher prevalence of infection and had significantly overall higher infection rates than did males. Males in the 2 to 5 year age group in Santa Catarina Palopo had lower prevalence rates for Cryptosporidium than the older males. However, significant differences $(\mathrm{p}<0.05)$ in the presence of Cryptosporidium were not found between age groups or genders in San Antonio Palopo.

Total prevalence rates for Cryptosporidium infections were high for both San Antonio Palopo and Santa Catarina Palopo, with an overall infection rate for both towns of $32 \%$ (Table 2). Prevalence rates for males were lower than those for females when the data from both villages were combined. Overall, males in the 2 to 5 year age group had a lower prevalence rate for cryptosporidiosis than did older male children.

The prevalence of infection recorded for January, in the dry season, was $29 \%$ and it was $35 \%$ for June, during the wet season (Table 3). Males, in the 2 to 5 year age group, exhibited significantly lower prevalence rates than did females, for both January and June. Males, between the ages of 2 and 10, had lower prevalence rates than did females in January. There was no significant difference $(\mathrm{p}<0.05)$ in the overall numbers of infected children due to the weather conditions. 
Table 1. Comparison of prevalence rates of Cryptosporidium between male and female children in villages around Lake Atitlan ${ }^{\mathrm{a}, \mathrm{b}}$

\begin{tabular}{|c|c|c|c|c|c|c|}
\hline \multirow[b]{2}{*}{ Age group } & \multicolumn{3}{|c|}{$\begin{array}{c}\text { San Antonio Palopo } \\
\text { Proportion (\% Infected) }\end{array}$} & \multicolumn{3}{|c|}{$\begin{array}{l}\text { Santa Catarina Palopo } \\
\text { Proportion ( } \% \text { Infected) }\end{array}$} \\
\hline & Males & Females & Total & Males & Females & Total \\
\hline $2-5$ & $2 / 10(20)$ & $4 / 9$ (44) & $6 / 19(32)$ & $3 / 19(16)^{c}$ & $5 / 9(56)^{d}$ & $8 / 28$ (29) \\
\hline $6-9$ & 2/7 (29) & $4 / 9$ (44) & $6 / 16(38)$ & 4/11 (36) & 1/3 (33) & $5 / 14(36)$ \\
\hline $10-13$ & $1 / 4(25)$ & 2/7 (29) & $3 / 11$ & 2/7 (29) & $2 / 5$ & $4 / 12(33)$ \\
\hline All ages & $5 / 21(24)$ & $10 / 25(40)$ & $15 / 46(33)$ & $9 / 37$ (24) & $8 / 17(47)^{d}$ & $17 / 54(31)$ \\
\hline
\end{tabular}

aStool samples were analyzed using Kinyoun's modified acid-fast stain.

${ }^{\mathrm{b}}$ Prevalence rates of infected males and females did not differ between villages.

${ }^{\mathrm{c}}$ Males 2 to 5 years old had significantly lower prevalence rates $(\mathrm{p}<0.05)$ than males in other age groups in the same village.

${ }^{\mathrm{d}}$ Females had significantly higher prevalence rates than males $(\mathrm{p}<0.05)$ in the same village.

Table 2. Prevalence rates of Cryptosporidium in males and females within age groups for both San Antonio Palopo and Santa Catarina Palopo ${ }^{\text {a }}$

\section{Proportion (\% Infected)}

\begin{tabular}{lcrr}
\hline Age group & Males & Females & Total \\
\hline $2-5$ & $5 / 29(17) \mathrm{b}, \mathrm{c}$ & $9 / 18(50)$ & $14 / 47(30)$ \\
$6-9$ & $6 / 18(33)$ & $5 / 12(42)$ & $11 / 30(37)$ \\
$10-13$ & $3 / 11(27)$ & $4 / 12(30)$ & $7 / 23(30)$ \\
All ages & $14 / 58(24) \mathrm{b}$ & $18 / 42(40)$ & $32 / 100(32)$ \\
\hline
\end{tabular}

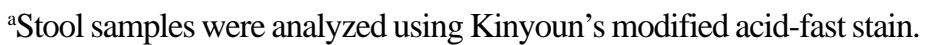

bPrevalence rates of males were significantly less than those of females $(p<0.05)$ within age groups.

${ }^{c}$ Males in the 2-5 age group had a lower prevalence rate $(\mathrm{p}<0.05)$ than males in the other age groups.

\section{Discussion}

The prevalence of cryptosporidiosis in children from Latin American countries varies from $2 \%$ to $31 \%$ [10], suggesting a high level of infection in Guatemalan villages and was the basis for this study. The demonstration of Cryptosporidium in children in villages around Lake Atitlan provided an opportunity to compare infection rates between geographically isolated villages that shared the same sources of infection by having the same flora, fauna, water source and life style risk factors. It was uncertain how often Cryptosporidium infections were acquired in these villages. The local environmental distribution of Cryptosporidium was dependent upon human, agricultural and wildlife sources and the significance of each individual source with regard to the presence of oocysts in the environment was unknown. Bovine reservoirs were considered as sources of human cryptosporidiosis, as previously demonstrated by Awad-El-Kariem [11,12]. There were few animal reservoirs of Cryptosporidium around the lake and they did not seem to have an effect on the prevalence rates of human infection, or if they did, the effect was hidden by the shared use of water.

Past studies of the effect of the weather on prevalence rates for cryptosporidiosis have had varying 
Table 3. Cryptosporidium infections in children: comparison of prevalence rates of males and females within age groups by season for San Antonio Palopo and Santa Catarina Palopo ${ }^{\mathrm{a}}$

\begin{tabular}{|c|c|c|c|c|c|c|}
\hline \multirow[b]{3}{*}{ Age group } & \multicolumn{3}{|c|}{ January } & \multicolumn{3}{|c|}{ June } \\
\hline & \multicolumn{3}{|c|}{ Proportion (\% Infected) } & \multicolumn{3}{|c|}{ Proportion (\% Infected) } \\
\hline & Males & Females & Total & Males & Females & Total \\
\hline $2-5$ & $3 / 17(18)^{\mathrm{b}}$ & $4 / 7$ (57) & $7 / 24(29)$ & $2 / 12(17)^{b}$ & $5 / 11$ & $7 / 23$ (30) \\
\hline $6-9$ & $2 / 8(25)^{\mathrm{b}}$ & $2 / 5(40)$ & $4 / 13(31)$ & $4 / 10(40)$ & $3 / 7$ & $7 / 17$ (41) \\
\hline $10-13$ & $1 / 5(20)$ & 2/7 (29) & $3 / 12(25)$ & $2 / 6$ & $2 / 5$ & 4/11 (36) \\
\hline All ages & $6 / 30(20)^{b}$ & $8 / 19$ (42) & $14 / 49$ (29) & $8 / 28(29)$ & $10 / 23$ & $18 / 51$ \\
\hline
\end{tabular}

aStool samples were analyzed using Kinyoun's modified acid-fast stain.

${ }^{b}$ Males in January and June had significantly lower prevalence rates $(\mathrm{p}<0.05)$ than did females.

results. High levels of infection are found in the dry season in Lima, Peru, 33\% [13], the United States, 22-27\% [14] and in Guatemala City, 8.3\% [5]. Other investigations found high prevalence rates during the wet seasons in the United States, 33-43\% [14], Mexico City, 11\% [6], in England and Wales, 2-22\% [15], and around Guatemala City, $1 \%$ [16].

In contrast, we found no significant differences in the levels of Cryptosporidium infections between seasons. The one consistent source of infection was the deep volcanic lake. The water level was constant and it was the main source for drinking, bathing and washing of household goods. It consisted of run-off water from the mountains around it, where the villages were located and where the villagers practiced very poor sanitation.

In our study, lake water was the most important method of Cryptosporidium transmission. Children had a tendency to be less aware of hygiene practices and played in dirt yards contaminated with fecal material. Chickens and dogs were commonly found roaming freely in each of the towns, resulting in widespread contamination of the soil with their feces. Cattle and other domestic animals were rarely seen, however, human feces were frequently found on the ground close to human dwellings.

A previous study of children with Cryptosporidium found that there were no significant differences in infection due to age or gender [17]. Our data, however, showed that males in the age group 2-5 years had fewer infections than did females ( $17 \%$ vs. $50 \%$, respectively, $\mathrm{p}<0.05)$, suggesting that the male's exposure to Cryptosporidium was affected by life style risk factors that increased the exposure of the females to the untreated water. Male and female children of ages 2-5 were basically treated the same by their parents, making their risk factors very similar, and the reasons for the highlevel of infection in this age group of female children were not obvious. Most males over 10 years of age were up on the mountain sides working in the fields during the day while the female children helped their mother washing clothes in the lake, cleaning and cooking, thus having more exposure to untreated water, increasing their risk of infection. There are quite likely several unidentified routes of disease spread in these villages and further studies are required to determine transmission patterns.

In conclusion, we observed a large number of Cryptosporidium infections in children living in two villages around Lake Atitlan, Guatemala, and we postulate that the lake water was responsible for transmission of the disease. The finding that children between the ages of 2 and 10 were highly susceptible (30-37\%) to infection with Cryptosporidium, and the high prevalence rate in females $(50 \%)$, suggested a difference in exposure to infections from that of male $(17 \%)$ children. There was an apparent consistency of infection during both the dry and wet seasons (significantly different infection rates were not 
observed) corresponding to a constant exposure to the untreated water supply, coming mainly from the lake.

This study extends the knowledge of the characteristics of Cryptosporidium infections by demonstrating that a constant source of contaminated water, regardless of the time of season, results in high prevalence rates in children, and sanitation practices determine the acquisition of infections. Further studies of risk factors in the villages are needed to identify the transmission patterns of cryptosporidiosis.

\section{Acknowledgements}

This work received financial support from an inhouse grant (HEL) and a President's Scholarship Award (CZB, JSP, ELG, HEL) from NSU. The assistance of numerous DOCARE International volunteers is appreciated.

\section{References}

1. Dubey J.P., Speer C.A., Fayer R. Cryptosporidiosis in Man and Animals. Boca Raton, Florida: CRC Press, 1990.

2. Fayer R., Morgan U., Upton S.J. Epidemiology of Cryptosporidium: transmission, detection and identification. Int J Parasitol 2000;30:1305-22.

3. Mac Kenzie W.R., Hoxie N.J., Proctor M.E., et al. A massive outbreak in Milwaukee of Cryptosporidium infection transmitted through the public water supply. N Eng J Med 1994;331:161-7.

4. Alles A.J., Waldron M.A., Sierra L.S., et al. Prospective comparison of direct immunofluorescence and conventional staining methods for detection of Giardia and Cryptosporidium spp. in human fecal specimens. J Clin Microbiol 1995;33:1632-4.

5. Cruz J.R., Cano F., Caceres P., et al. Infection and diarrhea caused by Cryptosporidium sp. among Guatemalan infants. J Clin Micro 1988;26:88-91.

6. Enriquez F.J., Avila C.R., Tanaka-Kido J.I., et al. Cryptosporidium infections in Mexican children: Clinical, nutritional, enteropathogenic and diagnostic evaluations. Am J Trop Med Hyg 1997;56:254-7.

7. Holley H.P., Jr, Dover C. Cryptosporidium spp., a common cause of parasitic diarrhea in otherwise healthy individuals. J Infect Dis 1986;153:365-8.
8. Henriksen S.A., Pohlenz J.F.L. Staining cryptosporidia by a modified Ziehl-Neelsen technique. Acta Vet Scand 1981;22:594-6.

9. Pagano M., Gauvreau K. Principles of Biostatistics, 2nd Edition, Duxbury, Pacific Grove, California: Duxbury Publishers, 2000.

10. Ungar B.L., Gilman R.H., Lanata C.F., et al. Seroepidemiology of Cryptosporidium infection in two Latin American populations. J Infect Dis 1988; 157:551556.

11. Awad-El-Kariem F.M., Robinson H.A., Dyson D.A., et al. Differentiation between human and animal isolates of Cryptosporidium parvum using molecular and biological markers. Parasitol 1995;110:129-32.

12. Awad-El-Kariem F.M., Robinson H.A., Dyson D.A., et al. Differentiation between human and animal isolates of Cryptosporidium parvum using molecular and biological markers. Parasitol Res 1998;84:297-301.

13. Bern C., Ortega Y., Checkley W., et al. Epidemiologic differences between cyclosporiasis and cryptosporidiosis in Peruvian children. Emerg Inf Dis 2002;8:581-585.

14. Amin O.M. Seasonal prevalence of intestinal parasites in the United States during 2000. Am J Trop Med Hyg 2002;66:799-803.

15. Smerdon W.J., Nichols T., Chalmers R.M., et al. Foot and Mouth Disease in livestock and reduced cryptosporidiosis in humans, England and Wales. Emerg Inf Dis 2003;9:22-8.

16. Bern C., Hernandez B., Lopez B., et al. The contrasting epidemiology of Cyclospora and Cryptosporidium among outpatients in Guatemala. Am J Trop Med Hyg 2000;63:231-5.

17. Xiao L., Bern C., Limor J., et al. Identification of 5 types of Cryptosporidium parasites in children in Lima, Peru. $\mathrm{J}$ Infect Dis 2001;183:492-7. 